http://jmscr.igmpublication.org/home/ ISSN (e)-2347-176x ISSN (p) 2455-0450

crossref DOI: https://dx.doi.org/10.18535/jmscr/v8i3.80

\author{
Journal Of Medical Science And Clinical Research \\ IGM Publication \\ An Official Publication of IGM Publication
}

\title{
A Study on Etiological Agents and their Antimicrobial susceptibility causing Chronic Suppurative Otitis Media in a Tertiary Care Hospital
}

\author{
Authors \\ Dr Vrutika V. Gandhi*, Dr M. Kalyani , Dr P. Neelu Sree, Dr B. Vivekanandan \\ *Corresponding Author \\ Dr Vrutika V. Gandhi
}

\begin{abstract}
Chronic suppurative otitis media (CSOM) is the most common cause of hearing impairment in the developing countries and it is associated with increased incidence of intracranial and extra cranial complications. To isolate, identify and characterize the Bacterial organisms and detect the antibacterial susceptibility pattern of the isolates by using microbiological methods from specimens of clinically proved cases of chronic suppurative otitis media. A total of 245 patients with CSOM were studied. Swabs were collected from each patient and cultured for bacteria and fungus. Standard methods for isolation and identification of bacteria and fungus were followed. Antibiotic susceptibility testing was done by KirbyBauer's disc diffusion method. Out of the 245 samples studied for bacterial and fungal isolates, 225 samples showed growth of pathogens, 20 samples did not show any growth, 201 samples showed bacterial growth, The most predominant organism was Staphylococcus aureus, 24 samples showed fungal growth, Aspergillus sps being the predominant isolate. Antibiotic sensitivity of organism altered over time, with needs for periodic bacteriological examination. Staphylococcus aureus being most common organism isolated is highly sensitive to cloxacillin and cephelexin. Patients would be benefited by accurate diagnosis of type of infection and the appropriate drug that will be sensitive for the infection can be administered to them.
\end{abstract}

Keywords: Chronic Suppurative otitis media, bacterial and fungal isolates, Staphylococcus aureus, Aspergillus species.

\section{Introduction}

Chronic suppurative otitis media (CSOM) is defined as infection of the middle ear three episodes per year that lasts for more than three months and is accompanied by otorrhea and tympanic membrane perforation.

Micro-organisms found in chronic discharge differ from those found in acute suppurative otitis media. The commonest organisms isolated are Pseudomonas aeruginosa, Proteus species (P. mirabilis and P. vulgaris) and Staphylococcus aureus. These organisms are most likely to gain access to the middle ear from the external auditory canal through the tympanic membrane defect. Other organisms found less commonly in chronically discharging ears include Escherichia coli, Streptococcus pneumoniae, Diphtheroids, Klebsiella species and the anerobic Bacteroides species.

Inspite of the decline in the incidence of acute suppurative otitis media with advent and use of antibiotics, the great frequency of chronic 
suppurative otitis media and its poor response to the routinely used antibiotics has prompted the present study. This study is primarily undertaken to determine the bacterial and fungal flora which are prevalent in the middle ear of patients suffering from chronic suppurative otitis media and in vitro susceptibility of different organisms

\section{Materials and Method}

This study was done for accurate diagnosis with the type of bacterial infection and the appropriate drug showing sensitivity could be administered to them over a period of one year, 245 samples were collected from patients attending the Department of Otorhinolaryngology, in a Tertiary care hospital All the Ear swab samples of patients diagnosed with tubotympanic type of CSOM sent by the ENT department were received at the Microbiology Laboratory.

\section{Sample processing}

One swab was used for performing gram staining and $\mathrm{KOH}$ mount and another swab was used for inoculating the culture media for aerobic bacterial culture. Nutrient agar, 5\% Sheep blood agar, Chocolate agar and Mc Conkey agar culture plates were inoculated and incubated for aerobic bacterial culture at $37^{\circ} \mathrm{C}$ for $18-24$ hours. The bacterial growth was identified based on the morphology of the bacterial colonies on culture plates and confirmed using the biochemical reactions as done routinely.

The antibiotic susceptibility testing of the bacterial isolates was performed as per Kirby Bauer's Disc Diffusion method in Mueller Hinton agar using the preferable antibiotics and interpretation was done based on Clinical Laboratory Standards Institute Guidelines (CLSI). Sample were processed for fungal examination using $10 \% \mathrm{KOH}$ mount and further inoculated on Sabouraud's dextrose agar and chrome agar for Isolation of fungus. It was incubated at $27^{\circ} \mathrm{C}$ and $37^{\circ} \mathrm{C}$ for $2-14$ days. The growth was identified based on their morphological and cultural characteristics and microscopic examination was done using lactophenol blue staining technique. All yeast isolates were subcultured on CHROM agar (HiMedia) and incubated at $37^{\circ} \mathrm{C}$ for 24 hours and the species were identified by type and colour of the colonies on CHROM agar media where C. albicans showed bluish green and C.tropicalis showed dark blue gray centre with pink halos. All the moulds were subjected to slide culture method. Colonies were identified according to standard mycological methods and identified as Aspergillus species.

\section{Result}

Among 245 samples of clinically proven CSOM patients in our study, 225 samples showed growth of pathogens, 20 samples did not show any growth, 201 samples showed bacterial growth and 24 samples showed fungal growth.

Majority $\mathrm{n}=72(35.82 \%)$ of the patient were in the age group 11 to 20 years irrespective of sex. In 21 to 30 years age group there were $n=34(16.91$ $\%)$ and in 61-70 years $n=12(5.9 \%)$

201 samples that showed bacterial growth, the most predominant organism $\mathrm{n}=65(32.33 \%)$ was Staphylococcus aureus followed by Pseudomonas aeruginosa $58(28.85 \%)$ as shown in figure no 1.

Staphylococcus aureus is the commonest organism in our study. Staphylococcus aureus isolates were highly sensitive to cloxacillin (93.84\%), cephalexin (92.30\%), Amikacin $(92.30 \%)$ as shown in figure no 2 .

Pseudomonas aeruginosa was the second highest number in isolation. They were highly sensitive to gentamicin (86.20\%), ofloxacin (77.58) and amikacin $(77.58 \%)$.

Of the 24 fungal culture positive cases, the predominantly isolated fungi were Aspergillus species. Among the Aspergillus, the predominant species were Aspergillus niger (15 isolates) and Aspergillus flavus (5 isolates). Candida albicans ( 2 isolates) and Candida tropicalis ( 2 isolates) were the commonly isolated species of Candida and Candida species as shown in figure no. 3 and table no 1. 


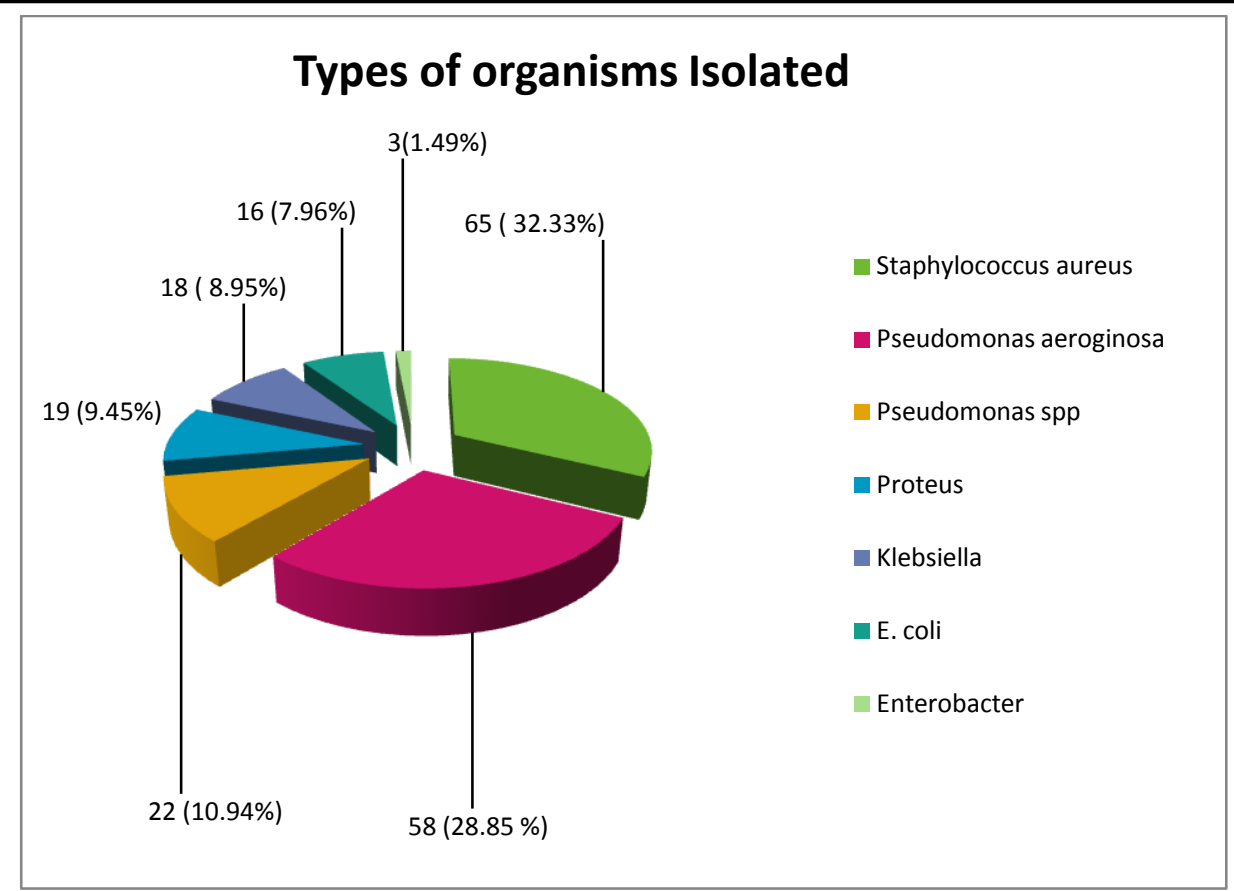

Figure no. 1 Types of organism isolated

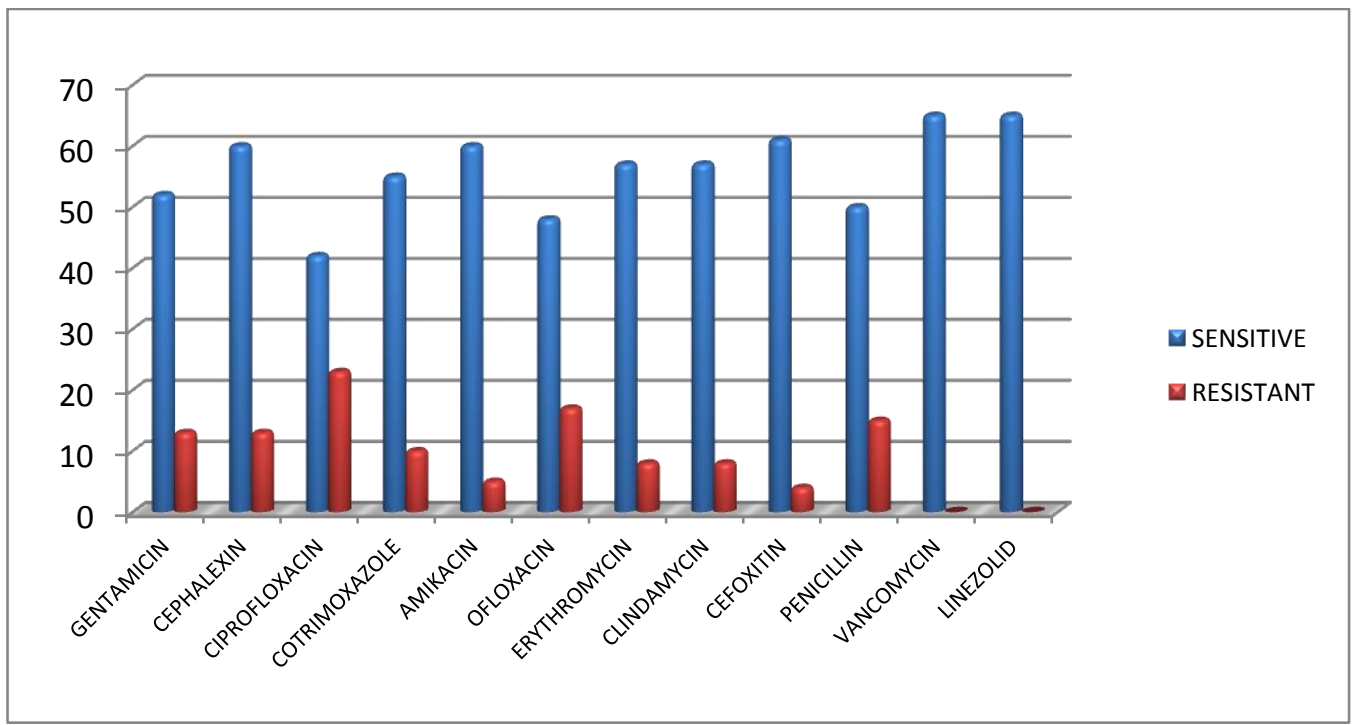

Figure no 2: Antibiotic sensitivity pattern - Staphylococcus aureus

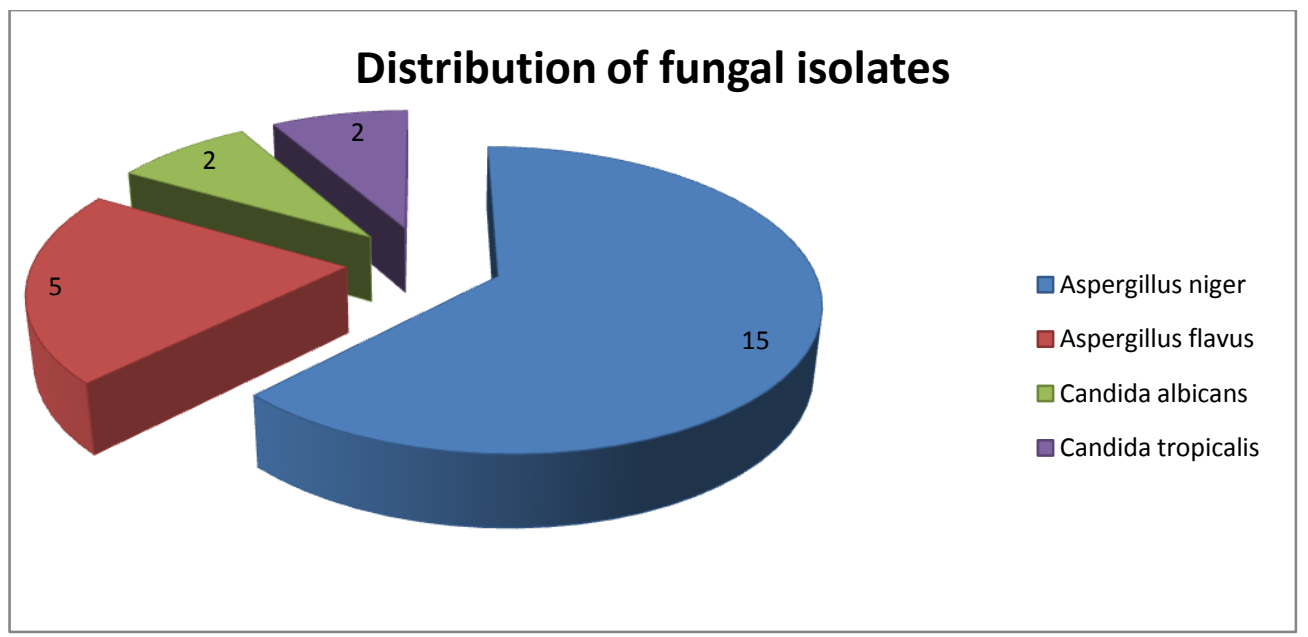

Figure no 3: Distribution of fungal isolates 
Table no 1. Distribution of the Aspergillus and Candida species

\begin{tabular}{|l|c|}
\hline Fungal Isolates & Total \\
\hline Aspergillus niger & $15(62.5 \%)$ \\
\hline Aspergillus flavus & $5(20.8 \%)$ \\
\hline Candida albicans & $2(8.3 \%)$ \\
\hline Candida tropicalis & $2(8.3 \%)$ \\
\hline
\end{tabular}

\section{Discussion}

Chronic suppurative otitis media is an important cause of morbidity in very large group of Indian population in the form of preventable hearing loss. In our study the average mean age is 32 years similar to other studies done by Aberg et $\mathrm{al}^{(1)}$ reported a mean age of 41 years, Vartiainen et al ${ }^{(2)}$ a mean age of 38 years, Alho et $\mathrm{al}^{(3)}$ a mean age of 42 years and Maharjan $M$ et $\mathrm{a}^{(4)}$ reported a mean age of 34 years.

Study done by Srivastava K.V. et al $(1979)^{(5)}$, Loy $\mathrm{AH}$ et al $(2002)^{(6)}$, Yeo SG et al $(2007)^{(7)}$, Nikakhlagh S. et al $(2008)^{(8)}$, the major organism isolated was Staphylococcus aureus followed by Pseudomonas aeruginosa which is similar to our study. Study done by Indudharan $R$. et al $(1999)^{(9)}$, Khanna V et al $(2000)^{(10)}$, Yang Y et al $(2001)^{(11)}$ Sharma S et al (2004) ${ }^{(12)}$, Vikram B K et al (2008)(13), Mansoor T. et al (2009) ${ }^{(14)}$, the major organism isolated was Pseudomonas aeruginosa followed by Staphylococcus. aureus which is in contrast to our study. Staphylococcus aureus is the commonest organism in our study. Staphylococcus aureus isolates were highly sensitive to cloxacillin (93.84\%), cephalexin (92.30\%), Amikacin (92.30\%).

A study conducted in South Korea, reported that in adult patients with chronic suppurative otitis media (CSOM), ciprofloxacin resistant Pseudomonas aeruginosa was found. In our study, Pseudomonas aeruginosa were found to be sensitive to ciprofloxacin (74.13\%) which shows the increasing trend of ciprofloxacin resistant strain in the community.

Among the fungal etiology in CSOM, the most commonly isolated organisms are Aspergillus species and Candida species (Ibekwe et al., 1997) ${ }^{(15) .}$ In our study, Aspergillus species comprised of $(83.3 \%)$ of the total fungal isolates, whereas $(16.6 \%)$ of the isolates were Candida species. A study by Talwar et al. ${ }^{(16)}$, from India reported higher isolation rate of Aspergillus species $(60.2 \%)$ as compared to Candida species $(17.6 \%)$.

\section{Conclusion}

Antibiotic sensitivity of organism altered over time, with needs for periodic bacteriological examination. Pre treatment antibiotic sensitivity test may help in selecting appropriate antibiotics for treatment.

Considering all these factors it is really a challenge for us to upgrade our health care system with National Control Programme to control chronic suppurative otitis media and prevent deafness caused by it.

\section{References}

1. Aberg B, Westin T, Tjellstrom A, Edstrom S. Clinical characteristics of cholesteatoma. Am J Otolaryngol, 1991; 12:254-8.

2. Vartianinen E. Changes in the clinical presentation of chronic otitis media from the 1970s to the 1990s. J Laryngol Otol 1998;112:1034-7

3. Alho OP, Jokinen $\mathrm{K}$, Laitakari $\mathrm{K}$, Palokangas J. Chronic suppurative otitis media and cholesteatoma. Vanishing iseases among Western populations. Clin Otolaryngol. 1997; 22: 358-61.

4. Maharjan M, Kafle P, Bista M, Shrestha S, $\mathrm{KC}$ Toran, Observation of hearing loss in patients with chronic suppurative otitis media tubotympanic type. Kathmandu University Medical Journal 2009, 7(28), 397-401.

5. Srivastava V.K, Agarwal S.K,. Malik G.K, Chronic suppurative otitis media in children. Indian Med J.1979,46,363.

6. Loy AH, Jan AL. Lu PK microbiology of chronic supparative otitis media in 
Singapore. Singapore Medical Journal 2002 Jun; 43(6) 296-9

7. Sharma S, Rehan HS, Goyal A, Jha AK. Upadhyaya S. Misha SC, Bacteriological profile in chronic supportive otitis media in Eastren Nepal; Tropical Doctor 2004, 34(2): 102-4.

8. Nikakhlagh S, Khossravi AD, Fazlipour A, Safarzadeh M, Microbiologic findings in patients with chronic suppurative otitis media, J.Med.Sci, 2008, 8(5); 503-506.

9. Yang Y. Gong S. Liu Y. Clinical investigation of bacteriology of chronic supparative otitis media. Lin Chung Er Bi Yan Hou Ke Za Zh. 2001 Dec. 15 (17) 550-7.

10. Sharma S, Rehan HS, Goyal A, Jha AK. Upadhyaya S. Misha SC, Bacteriological profile in chronic supportive otitis media in Eastren Nepal; Tropical Doctor 2004, 34(2): 102-4.

11. Vikram BK, Khaja N, Udayashankar SG, Venkatesha BK, Manjunath D, Clinico epidemiological study of complicated and uncomplicated chronic suppurative otitis media, The Journal of Laryngology \& Otology (2008), 122, 442-446.

12. Mansoor T, Musani MA, Khalid G, Kamal M, Pseudomonas aeruginosa in chronic suppurative otitis media: sensitivity spectrum against various antibiotics in Karachi, $J$ Ayub Med Coll Abbottabad 2009;21(2),120-123.

13. Loy AH, Jan AL. Lu PK microbiology of chronic supparative otitis media in Singapore. Singapore Medical Journal 2002 Jun; 43(6) 296-9
14. Jang $\mathrm{CH} \&$ Park SY, Emergence of ciprofloxacin-resistant pseudomonas in chronic suppurative otitis media, Clin. Otolaryngol. 2004, 29, 321-323.

15. Ibekwe AO, al Shareef Z, Benayam A. Anaerobes and fungi in chronic suppurative otitis media. Ann Otol Rhinol Laryngol 1997;106:649-52.

16. Talwar P, Chakrabarti A, Kaur P, Pahwa RK, Mittal A, Mehra YN. Fungal infections of ear with special reference to chronic suppurative otitis media. Mycopathologia 1988;104:47. 